\title{
Micromechanical modeling of nacre-mimetic Ti3C2-MXene nanocomposites with viscoelastic polymer matrix
}

\author{
Srivatsa, Shreyas; Packo, Pawel; Mishnaevsky Jr., Leon; Uhl, Tadeusz; Grabowski, Krzysztof
}

Published in:

MRS Advances

Link to article, DOI:

$10.1557 / \mathrm{s} 43580-021-00085-2$

Publication date:

2021

Document Version

Publisher's PDF, also known as Version of record

Link back to DTU Orbit

Citation (APA):

Srivatsa, S., Packo, P., Mishnaevsky Jr., L., Uhl, T., \& Grabowski, K. (2021). Micromechanical modeling of nacre-mimetic $\mathrm{Ti}_{3} \mathrm{C}_{2}-\mathrm{MXene}$ nanocomposites with viscoelastic polymer matrix. MRS Advances, 6, 729-733. https://doi.org/1031557/s43580-021-00085-2

\section{General rights}

Copyright and moral rights for the publications made accessible in the public portal are retained by the authors and/or other copyright owners and it is a condition of accessing publications that users recognise and abide by the legal requirements associated with these rights.

- Users may download and print one copy of any publication from the public portal for the purpose of private study or research.

- You may not further distribute the material or use it for any profit-making activity or commercial gain

- You may freely distribute the URL identifying the publication in the public portal 


\title{
Micromechanical modeling of nacre-mimetic $\mathrm{Ti}_{3} \mathrm{C}_{2}$-MXene nanocomposites with viscoelastic polymer matrix
}

\author{
Shreyas Srivatsa ${ }^{1}$ [ $\cdot$ Pawel Packo ${ }^{2} \cdot$ Leon Mishnaevsky Jr. ${ }^{3} \cdot$ Tadeusz Uhl $^{1,2} \cdot \mathrm{Krzysztof} \mathrm{Grabowski}^{1,2}$
}

Received: 17 May 2021 / Accepted: 10 June 2021 / Published online: 22 June 2021

(c) The Author(s) 2021

\begin{abstract}
A new two-dimensional nanomaterial-Titanium Carbide MXene $\left(\mathrm{Ti}_{3} \mathrm{C}_{2}\right.$-MXene) - was reported in 2011. In this work, the microscale models of $\mathrm{Ti}_{3} \mathrm{C}_{2}$-MXene nanomaterial are considered with polymer matrix. The nanocomposites are modeled using nacre-mimetic brick-and-mortar assembly configurations due to enhanced mechanical properties and interlocking mechanism between the $\mathrm{Ti}_{3} \mathrm{C}_{2}$-MXene (brick) and polymer matrices (mortar). The polymer matrix material (Epoxy-resin) is modeled with elastic and viscoelastic behavior (Kelvin-Voigt Model). The Finite Element Method is used for numerical analysis of the microscale models with the multi-point constraint method to include $\mathrm{Ti}_{3} \mathrm{C}_{2}$-MXene fillers in the polymer matrix. $\mathrm{Ti}_{3} \mathrm{C}_{2}$-MXenes are considered as thick plate elements with transverse shear effects. The response of elastic and viscoelastic models of polymer matrix are studied. Finally, a tensile and compressive load is applied at the microscale and the effective load transfer due to nacre-mimetic configuration is discussed. This paper provides nacre-mimetic models to pre-design the nanocomposite for optimal performance with damage resistance and enhanced strength.
\end{abstract}

\section{Introduction}

MXenes are two-dimensional (2D) nanomaterials discovered in 2011 [1]. Titanium Carbide MXenes $\left(\mathrm{Ti}_{3} \mathrm{C}_{2}\right.$-MXenes) was the first inorganic 2D nanomaterial discovered and was synthesized by etching the precursor MAX phase compoundTitanium Aluminum Carbide $\left(\mathrm{Ti}_{3} \mathrm{AlC}_{2}\right)$. Over the past decade, various investigations on the physical and chemical properties of MXenes [2-4] have been conducted and optimization challenges of the synthesis process of MXenes have also been addressed [5]. $\mathrm{Ti}_{3} \mathrm{C}_{2}$-MXenes have also been used to form nanocomposites in the literature with the use of polymers as matrix material [6]. The experimental investigations of the $\mathrm{Ti}_{3} \mathrm{C}_{2}$-MXenes/Polymer nanocomposites have provided promising results with regards to tailoring the physical properties of the nanocomposites like conductivity [7, 8], elasticity [9], and tensile strength [7, 9,

Shreyas Srivatsa

sshreyas@agh.edu.pl

1 Academic Center for Materials and Nanotechnology, AGH University of Science and Technology, Krakow, Poland

2 Department of Robotics and Mechatronics, AGH University of Science and Technology, Krakow, Poland

3 Department of Wind Energy, Technical University of Denmark, 4000 Roskilde, Denmark
10], electromagnetic shielding [11], etc. These demonstrations emphasize the importance of good electromechanical properties of $\mathrm{Ti}_{3} \mathrm{C}_{2}$-MXenes for use with polymers to form nanocomposites. Along with the classical process of vacuum-assisted filtration to form films of $\mathrm{Ti}_{3} \mathrm{C}_{2}$-MXene and $\mathrm{Ti}_{3} \mathrm{C}_{2}$-MXene nanocomposites $\left(\mathrm{Ti}_{3} \mathrm{C}_{2}\right.$-MXNC) for various applications, there have been recent developments of using bioinspired nacre-mimetic brick-and-mortar assembly of MXenes with polymers in the literature [10, 12]; that promise both good physical properties and an option to tailor the physical properties with the pre-design of the nacre-mimetic assembly process.

Along with the experimental investigations into $\mathrm{Ti}_{3} \mathrm{C}_{2}-\mathrm{MXenes}$ and its nanocomposite properties, there has been mathematical modeling of the $\mathrm{Ti}_{3} \mathrm{C}_{2}$-MXNC. There have been applications of both analytical and numerical methods available in continuum mechanics theory to $\mathrm{Ti}_{3} \mathrm{C}_{2}-\mathrm{MXNC}$ at the microscale [13-15]. All these works consider the elastic behavior of polymer matrices. With the formation of polymer nanocomposites, the viscoelastic properties of the polymers would play a major role in the nonlinear response of the stress-strain behavior which is observed with many tensile tests conducted on the $\mathrm{Ti}_{3} \mathrm{C}_{2}$-MXNC samples [7]. In this paper, the response of the $\mathrm{Ti}_{3} \mathrm{C}_{2}$-MXNC is studied using an epoxy-resin polymer matrix, subjected to quasi-static tensile load. Bioinspired 
nacre-mimetic brick-and-mortar assembly micromechanical modeling along with finite element analysis (FEA) technique (numerical method) is used for these nanocomposites [16]. The polymer matrices are modeled with elastic and viscoelastic (Kelvin-Voigt) behavior. The effective load transfer capability of $\mathrm{Ti}_{3} \mathrm{C}_{2}$-MXNC is described using the quasi-static compressive loading for elastic behavior of the $\mathrm{Ti}_{3} \mathrm{C}_{2}$-MXene/Epoxy-resin nanocomposite. The properties, modeling, and results are discussed in the succeeding sections. For modeling purposes, the weight fraction of MXene and polymers are used in this paper and the units used are $\mathrm{mm}, \mathrm{N}, \mathrm{t} / \mathrm{mm}^{3}$ unless otherwise stated.

\section{Modeling and methods}

\section{Geometric and elastic properties of $\mathrm{Ti}_{3} \mathrm{C}_{2}$-MXene}

$\mathrm{Ti}_{3} \mathrm{C}_{2}$-MXene monolayers are modeled as a $2 \mathrm{D}$ sheet with lateral dimensions of 2 microns and thickness of 2 nanometers for modeling in FEA software-MSC Marc. The elastic properties of $\mathrm{Ti}_{3} \mathrm{C}_{2}$-MXene [17] are: Young's modulus $(E)$ of $312.5 \mathrm{GPa}$, Poisson's ratio $(\mu)$ of 0.2265 , Shear modulus $(G)$ of $141 \mathrm{GPa}$, Density $(\rho)$ of $\sim 3.2 \times 10^{-9} \mathrm{tmm}^{-3}$ and maximum allowable tensile strength of $17.3 \pm 1.6 \mathrm{GPa}$.

\section{Elastic properties of epoxy-resin}

The material properties of the epoxy-resin polymer used in this paper are [16]: Young's modulus $(E)$ of $3.0741 \mathrm{GPa}$, Poisson's ratio $(\mu)$ of 0.29 , density $(\rho)$ of $1.1 \times 10^{-9} \mathrm{tmm}^{-3}$, and allowable maximum stress of $49.9 \mathrm{MPa}$.

\section{Viscoelastic modeling of epoxy-resin polymer}

Viscoelasticity involves both elastic and viscous behavior modeled together. Among the general viscoelastic models used for polymers, Kelvin-Voigt (KV) model is quite popular and simple for usage. This allows for the rate of change of inelastic strain to be a function of total stress and previously calculated strain in the integration process. An addition creep strain $\left(\varepsilon_{i j}^{k}\right)$ is assumed with the general elastic model to implement the KV model in MSC Marc [18]. The constitutive relationship is defined by the equation below, where $\sigma_{k l}^{k}$ is deviatoric stress at the end of increment of time.

$\frac{\mathrm{d}}{\mathrm{d} t} \varepsilon_{i j}^{k}=A_{i j k l} \sigma_{k l}^{k}-B_{i j k l} \varepsilon_{k l}^{k}$
The total strain is given by Eq. (2) below which contains the instantaneous elastic strain component $\varepsilon_{i j}^{e}$, and KV model strain component $\varepsilon_{i j}^{k}$ defined by Eq. (1). The time dependency of the strain components introduces the viscoelastic behavior to the implemented models and simulations.

$\varepsilon_{i j}=\varepsilon_{i j}^{e}+\varepsilon_{i j}^{k}$

\section{Numerical modeling of $\mathrm{Ti}_{3} \mathrm{C}_{2}-\mathrm{MXene} /$ epoxy-resin nanocomposite}

The finite element method-based numerical method is used for the analysis of the micromechanical models developed in this paper. The multi-point constraints (MPCs) method available in the FEA environment is used to embed the 2D MXene sheets in the polymer matrix, thus, linking the nodal degrees of freedom of the MXene 2D element with the polymer matrix element. MXene monolayer or flakes of the dimensions mentioned in "Geometric and Elastic properties of $\mathrm{Ti}_{3} \mathrm{C}_{2}$-MXene" section are created using thick plate elements in MSC Marc software [15] to construct the microscale model. These MXene flakes are embedded in an epoxy-resin matrix which forms the representative volume element (RVE) structure used for analysis. The perfectly bonded interface assumption is used between the MXenes and epoxy-resin polymer to set up the MPC equations. The MXene flakes with the elastic properties provided in "Geometric and Elastic properties of $\mathrm{Ti}_{3} \mathrm{C}_{2}$-MXene" section are distributed in the polymer matrix based on bioinspired nacre-mimetic brick-and-mortar assembly [15] to provide enhanced and controllable mechanical properties for the $\mathrm{Ti}_{3} \mathrm{C}_{2}$-MXNC.

The RVE cube of $3.3 \mu \mathrm{m}$ as the side length is considered. This RVE cube is assigned the epoxy-resin material properties and subdivided into several eight-node threedimensional brick elements with trilinear interpolation. While the thick plate elements used for the $\mathrm{Ti}_{3} \mathrm{C}_{2}$-MXene flakes use a modified version of the first-order shear deformation theory to incorporate formulation of parabolic distribution of transverse shear strains and satisfies the zero transverse shear stress requirements on the plate surface. Virtual tensile and compression quasi-static loading is applied to the RVE models simulating the physical testing conditions in the universal testing machine. To study the micromechanical model response, the quasi-static uniaxial displacement boundary condition is provided at one end and fixed boundary condition at the other for the tensile loads [19]. While one end of the RVE is fixed when a uniaxial compressive load is applied to the models. Finally, the load-displacement relationship of the RVE 
with viscoelastic matrix behavior is found using the tensile loading condition.

\section{Results}

\section{Elastic and viscoelastic response of the $\mathrm{Ti}_{3} \mathrm{C}_{2}-\mathrm{MXene} /$ epoxy-resin nanocomposite with quasi-static tensile load}

The $\mathrm{Ti}_{3} \mathrm{C}_{2}$-MXene/Epoxy-resin nanocomposite micromechanical model is implemented with 15 and $40 \mathrm{wt} \%$ of
$\mathrm{Ti}_{3} \mathrm{C}_{2}$-MXene in the epoxy-resin matrix. The qualitative responses of the microscale models for the elastic matrix model are shown in Fig. 1a. Figure 1b includes a variation of the damping ratio $(c)$ for the $\mathrm{KV}$ model from 0.05 to 0.5 for both 15 and $40 \mathrm{wt} \%$ of $\mathrm{Ti}_{3} \mathrm{C}_{2}$-MXene/Epoxy-resin nanocomposite models, demonstrating the effect of damping on the overall MXNC material response. With the increase in the weight fraction of $\mathrm{Ti}_{3} \mathrm{C}_{2}$-MXNC from 15 to $40 \%$, the stiffness of the equivalent elastic model (simplified spring model capturing the effective behavior) increases from 140 to 270 $\mathrm{N} / \mathrm{m}$ (from elastic response plotted in Fig. 1b). The estimates of the effective Young's modulus of the $\mathrm{Ti}_{3} \mathrm{C}_{2}-\mathrm{MXNC}$ are

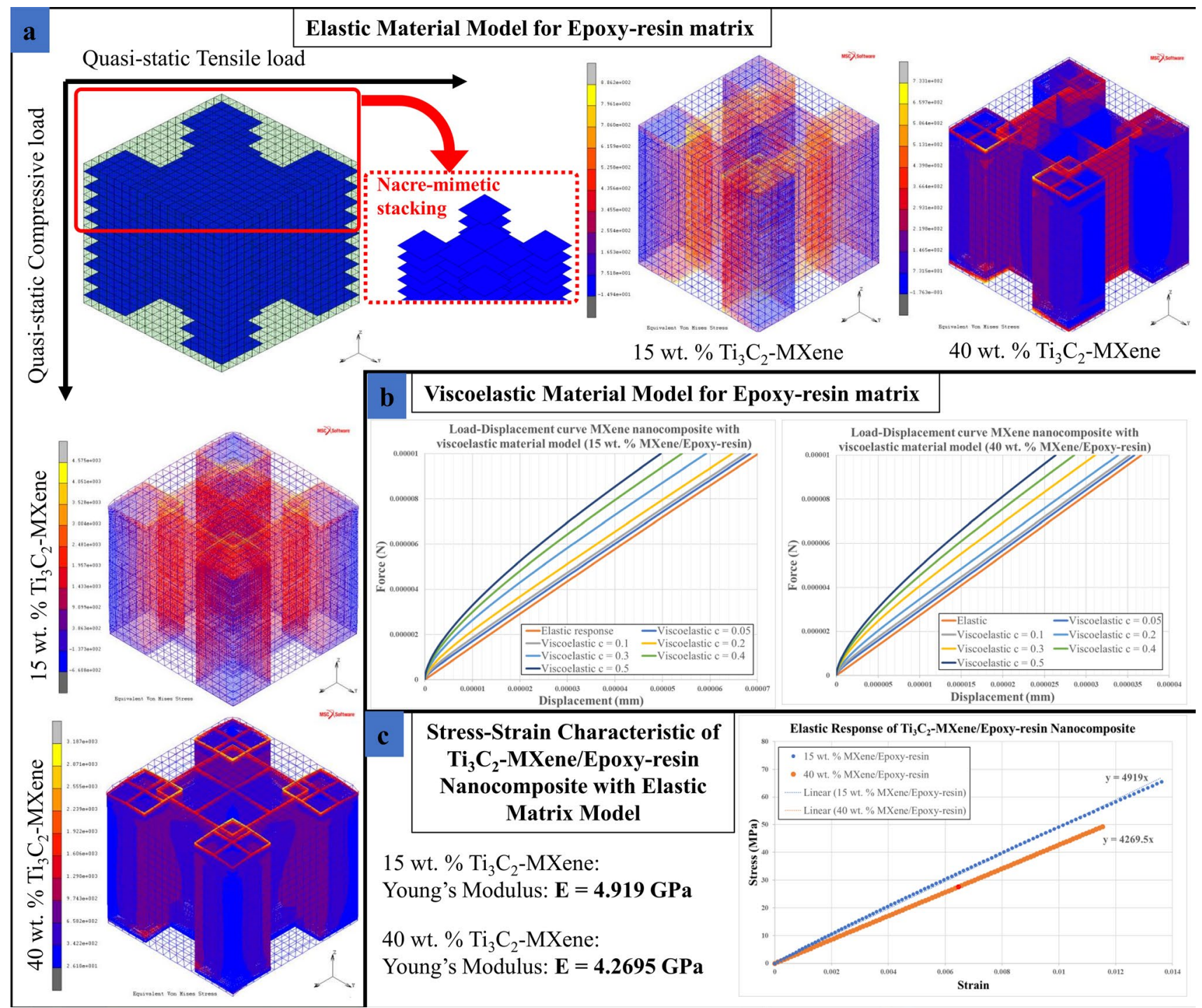

Fig. 1 a Elastic material model of epoxy-resin is used for $15 \mathrm{wt} \%$ and $40 \mathrm{wt} \%$ MXene/Epoxy-resin nanocomposite with quasi-static loading $(1 \mathrm{e}-6 \mathrm{~N})$ being compressive in the vertical direction (downward) and tensile in the horizontal direction (right). All the analysis results are shown with the equivalent Von-mises stress distribution. b The load $\mathrm{v} / \mathrm{s}$ displacement characteristics of the quasi-static virtual tensile tests conducted on both $15 \mathrm{wt} \%$ and $40 \mathrm{wt} \%$ MXene/Epoxyresin nanocomposite are plotted. The epoxy-resin matrix material is modeled with Kelvin-Voigt viscoelastic model in MSC Marc. c Numerical results of the stress-strain relationship for $15 \mathrm{wt} \%$ and 40 wt $\%$ MXene/Epoxy-resin nanocomposite models are provided with Young's modulus estimations 
4.919 and $4.2695 \mathrm{GPa}$ for 15 and $40 \mathrm{wt} \%$ of $\mathrm{Ti}_{3} \mathrm{C}_{2}$-MXene in the epoxy-resin matrix, respectively, shown in Fig. 1c.

\section{Elastic response of the $\mathrm{Ti}_{3} \mathrm{C}_{2}$-MXene/epoxy-resin nanocomposite with a quasi-static compressive load}

The nanocomposites models with the same weight fractions described in "Elastic and viscoelastic response of the $\mathrm{Ti}_{3} \mathrm{C}_{2}$-MXene/epoxy-resin nanocomposite with quasi-static tensile load" section are subjected to compressive load, where the loading is perpendicular to the stacking of the MXenes in the bioinspired configuration. The qualitative responses of the microscale models are given in Fig. 1a.

\section{Discussion and conclusions}

The bioinspired nacre-mimetic brick-and-mortar assembly model of $\mathrm{Ti}_{3} \mathrm{C}_{2}$-MXene in an epoxy-resin polymer matrix is developed with both elastic and viscoelastic material properties of the polymer. The microscale models are implemented with the multi-point constraints method in FEA with $\mathrm{Ti}_{3} \mathrm{C}_{2}$-MXene embedded inside the polymer with the nacre-mimetic configuration. The nacre-mimetic topological distribution of $\mathrm{Ti}_{3} \mathrm{C}_{2}$-MXene flakes results in an interlocking mechanism at the flake edges. The nacre-mimetic assembly configuration provides an opportunity to tailor the polymer intercalation between the $\mathrm{Ti}_{3} \mathrm{C}_{2}$-MXene flakes by assembly control; this also helps in the pre-design of the nanocomposite before the experimentation and in estimating the elastic properties of the composite. The results with elastic material behavior of the epoxy-resin with both tensile and compressive load indicate effective load transfer from the polymer to the $\mathrm{Ti}_{3} \mathrm{C}_{2}$-MXene flakes or filler material, thus, resulting in increased load-bearing capacity of the $\mathrm{Ti}_{3} \mathrm{C}_{2}$-MXNC. This is also due to the interlocking mechanism provided by the nacre-mimetic distribution. The viscoelastic material model of the polymer allows for the nonlinear response behavior of the nanocomposite to be modeled and an initial implementation with results is provided in this paper. The ability to control the assembly of $\mathrm{Ti}_{3} \mathrm{C}_{2}$-MXene in polymer, demonstrated in the literature, is modeled within the numerical method framework to design nanocomposites. Such a design approach can result in the increased mechanical performance of the nanocomposite by considering the trade-off between the load beading capacity and the damage propagation path. Finally, the nacre-mimetic modeling of $\mathrm{Ti}_{3} \mathrm{C}_{2}$-MXNC in combination with the experimental methods would result in effective implementation in mechanical and aerospace applications.

Acknowledgements Shreyas Srivatsa and Tadeusz Uhl received funding for this work from the European Union's Horizon 2020 research and innovation programme (DyVirt—Dynamic Virtualization: modeling performance of engineering structures) under the Marie SkłodowskaCurie Grant Agreement No. 764547.

Data availability Data sharing not applicable to this article as no datasets were generated or analyzed during the current study.

\section{Declarations}

Conflict of interest There are no conflicts to declare.

Open Access This article is licensed under a Creative Commons Attribution 4.0 International License, which permits use, sharing, adaptation, distribution and reproduction in any medium or format, as long as you give appropriate credit to the original author(s) and the source, provide a link to the Creative Commons licence, and indicate if changes were made. The images or other third party material in this article are included in the article's Creative Commons licence, unless indicated otherwise in a credit line to the material. If material is not included in the article's Creative Commons licence and your intended use is not permitted by statutory regulation or exceeds the permitted use, you will need to obtain permission directly from the copyright holder. To view a copy of this licence, visit http://creativecommons.org/licenses/by/4.0/.

\section{References}

1. M. Naguib, M. Kurtoglu, V. Presser, J. Lu, J. Niu, M. Heon, L. Hultman, Y. Gogotsi, M.W. Barsoum, Two-dimensional nanocrystals produced by exfoliation of Ti3AlC2. Adv. Mater. 23, 42484253 (2011). https://doi.org/10.1002/adma.201102306

2. V.M. Hong Ng, H. Huang, K. Zhou, P.S. Lee, W. Que, J.Z. Xu, L.B. Kong, Recent progress in layered transition metal carbides and/or nitrides (MXenes) and their composites: synthesis and applications. J. Mater. Chem. A 5, 3039-3068 (2017). https:// doi.org/10.1039/c6ta06772g

3. J. Pang, R.G. Mendes, A. Bachmatiuk, L. Zhao, H.Q. Ta, T. Gemming, H. Liu, Z. Liu, M.H. Rummeli, Applications of 2D MXenes in energy conversion and storage systems. Chem. Soc. Rev. 48, 72-133 (2019). https://doi.org/10.1039/c8cs00324f

4. X. Zhan, C. Si, J. Zhou, Z. Sun, MXene and MXene-based composites: synthesis, properties and environment-related applications. Nanoscale Horizons. 5, 235-258 (2020). https://doi.org/ 10.1039/c9nh00571d

5. M. Alhabeb, K. Maleski, B. Anasori, P. Lelyukh, L. Clark, S. Sin, Y. Gogotsi, Guidelines for synthesis and processing of two-dimensional titanium carbide (Ti 3 C 2 T x MXene). Chem. Mater. 29, 7633-7644 (2017). https://doi.org/10.1021/acs.chemmater.7b028 47

6. M. Carey, M.W. Barsoum, MXene polymer nanocomposites: a review. Mater. Today Adv. 9, 100120 (2021). https://doi.org/10. 1016/j.mtadv.2020.100120

7. Z. Ling, C.E. Ren, M.-Q. Zhao, J. Yang, J.M. Giammarco, J. Qiu, M.W. Barsoum, Y. Gogotsi, Flexible and conductive MXene films and nanocomposites with high capacitance. Proc. Natl. Acad. Sci. USA 111, 16676-16681 (2014). https://doi.org/10.1073/pnas. 1414215111

8. M.Q. Zhao, C.E. Ren, Z. Ling, M.R. Lukatskaya, C. Zhang, K.L. Van Aken, M.W. Barsoum, Y. Gogotsi, Flexible MXene/carbon nanotube composite paper with high volumetric capacitance. Adv. Mater. 27, 339-345 (2015). https://doi.org/10.1002/adma.20140 4140 
9. A. Lipatov, H. Lu, M. Alhabeb, B. Anasori, A. Gruverman, Y. Gogotsi, A. Sinitskii, Elastic properties of 2D Ti3C2Tx MXene monolayers and bilayers. Sci. Adv. 4, eaat0491 (2018). https://doi. org/10.1126/sciadv.aat0491

10. J. Lipton, G.M. Weng, M. Alhabeb, K. Maleski, F. Antonio, J. Kong, Y. Gogotsi, A.D. Taylor, Mechanically strong and electrically conductive multilayer MXene nanocomposites. Nanoscale 11, 20295-20300 (2019). https://doi.org/10.1039/c9nr06015d

11. F. Shahzad, M. Alhabeb, C.B. Hatter, B. Anasori, S.M. Hong, C.M. Koo, Y. Gogotsi, Electromagnetic interference shielding with 2D transition metal carbides (MXenes). Science 353, 11371140 (2016). https://doi.org/10.1126/science.aag2421

12. X. Shi, H. Wang, X. Xie, Q. Xue, J. Zhang, S. Kang, C. Wang, J. Liang, Y. Chen, Bioinspired ultrasensitive and stretchable mxene-based strain sensor via nacre-mimetic microscale "Brickand-Mortar" architecture. ACS Nano 13, 649-659 (2019). https:// doi.org/10.1021/acsnano.8b07805

13. C.B. Hatter, J. Shah, B. Anasori, Y. Gogotsi, Micromechanical response of two-dimensional transition metal carbonitride (MXene) reinforced epoxy composites. Compos. Part B Eng. 182, 107603 (2020). https://doi.org/10.1016/j.compositesb.2019. 107603
14. G. Monastyreckis, L. Mishnaevsky, C.B. Hatter, A. Aniskevich, Y. Gogotsi, D. Zeleniakiene, Micromechanical modeling of $\{$ MXene $\}$-polymer composites. Carbon N. Y. 162, 402-409 (2020). https://doi.org/10.1016/j.carbon.2020.02.070

15. S. Srivatsa, P. Paćko, L. Mishnaevsky, T. Uhl, K. Grabowski, Deformation of bioinspired MXene-based polymer composites with brick and mortar structures: a computational analysis. Materials 13, 1-19 (2020). https://doi.org/10.3390/ma13225189

16. S. Srivatsa, P. Paćko, L. Mishnaevsky, T. Uhl, K. Grabowski, Deformation of bioinspired MXene-based polymer composites with brick and mortar structures: a computational analysis. Materials 13, 5189 (2020). https://doi.org/10.3390/ma13225189

17. Z.H. Fu, Q.F. Zhang, D. Legut, C. Si, T.C. Germann, T. Lookman, S.Y. Du, J.S. Francisco, R.F. Zhang, Stabilization and strengthening effects of functional groups in two-dimensional titanium carbide. Phys. Rev. B 104103, 1-10 (2016). https://doi.org/10. 1103/PhysRevB.94.104103

18. MSC. Software, Marc 2013 Volume B: Element Library (2013)

19. G. Dai, L. Mishnaevsky, Graphene reinforced nanocomposites: 3D simulation of damage and fracture. Comput. Mater. Sci. 95, 684-692 (2014). https://doi.org/10.1016/j.commatsci.2014.08.011 